\title{
Influence of dietary factors on colorectal cancer survival
}

\author{
X Dray, M-C Boutron-Ruault, S Bertrais, D Sapinho, A-M Benhamiche-Bouvier, J Faivre
}

Gut 2003;52:868-873

Background: Diet has been identified as a major determinant of colorectal cancer (CRC) but little is known of its influence on CRC survival.

Aims: To study the influence of dietary factors on survival in patients who had undergone potentially curative CRC surgery.

Patients: Among 171 patients included in a case control study of CRC aetiological factors, 10 year survival data on 148 patients who underwent resection of the fumour for potential cure were obtained from a Registry of Digestive Tumours.

Methods: Tertiles of food and nutrient intakes were entered into Cox proportional hazards survival models, controlling for age, sex, tumour stage, and tumour location.

See end of article for authors' affiliations

Correspondence to:

Dr M-C Boutron-Ruault,

ISTNA, CNAM, 5 rue

Vertbois, 75003 Paris

France; boutron@cnam.fr

Accepted for publication

17 December 2002
Results: Only five year survival was influenced by the pre-diagnosis diet. High energy intake, as a result of high carbohydrate, protein, and lipid intake, was strongly related to increased survival. Five year relative risk of death for the highest versus the two lowest tertiles of energy intake was $0.18195 \%$ confidence interval $0.07 ; 0.44)$. This effect was similar in both sexes, for the colon and for the rectum. It was stronger in patients with $\mathrm{N}+/ \mathrm{M}+$ tumours (relative risk 0.06 ) than in those with less advanced tumours (relative risk 0.37; stage-energy interaction term non-significant). No specific food or nutrient could be identified as having prognostic significance.

Conclusions: Whether high energy intake selects less severe tumoral clones or modifies antitumoral immunity remains unclear. Larger series need to be investigated before conducting intervention studies but our findings should prompt nutritional follow up in CRC patients.

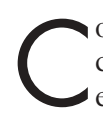
olorectal cancer (CRC) is one of the most common cancers in the Western world. It is widely accepted that environmental factors, especially dietary factors, are involved in the aetiology of CRC. High intakes of fat, red meat, refined sugar, and energy have been associated with an increased risk of $\mathrm{CRC}^{1-4}$ On the other hand, vegetable consumption is often related to a decreased risk of CRC. ${ }^{5} \mathrm{CRC}$ survival is poor, with an overall five year survival rate of approximately $45 \%{ }^{7}$ Stage at diagnosis and possibility of resection of the tumour for cure are the main prognostic factors. Sex, age at the time of diagnosis, ${ }^{7}$ tumour site, ${ }^{8}$ and socioeconomic status ${ }^{9}$ have also been discussed as determinants of survival. Although the relationship between diet and CRC has been extensively studied, its influence on survival has been examined in only one study to date, ${ }^{10}$ while diet was associated with the prognosis of cancers of the lung, prostate, ${ }^{12}$ and breast. ${ }^{13}$ The aim of this study was to assess the influence of pre-diagnosis diet on five year and 10 year survival of patients who underwent resection of CRC for potential cure.

\section{PATIENTS AND METHODS Study population}

A case control study on the relationship between colorectal neoplasms and diet was conducted between 1985 and 1987 in the Côte d'Or area (Burgundy, France) to investigate risk factors in colorectal tumours. The present study included the colorectal cancer (CRC) cases from the case control study. Details of the studied population have been presented elsewhere.$^{14}$ Briefly, patients were recruited from all gastroenterologists (public and private practices) in the area covered by a registry of digestive tumours. To meet a well defined eligibility, patients had to be residents of the Côte d'Or area, aged 30-79 years old, and had to present with a histologically proven primary CRC for the first time. Criteria for exclusion were polyposis coli, inflammatory bowel disease, previous colectomy, and previous cancer. Histopathological diagnosis was performed in the two laboratories that centralised all pathological examinations in the area and collaborated with the Registry of Digestive Tumours of the Côte d'Or. A total of 171 CRC cases ( 109 men, 62 women) were included in the case control study, with a participation rate of $79.9 \%$. Palliative surgery, absence of surgery, and death within one month of tumour resection (even when curative) were additional exclusion criteria in the present study.

\section{Data ascertainment}

Individual and clinical data were obtained from medical files and recorded in the Registry of Digestive Tumours of the Côte d'Or. Tumour location was classified according to the International Classification of Diseases for Oncology, 9th revision, as colonic or rectal cancer. Stage at diagnosis was coded according to Dukes' classification, ${ }^{15}$ and correspondence with the TNM classification ${ }^{16}$ was as follows: Dukes' A, tumour infiltrating the submucosa or the lamina propria (T1-T2 N0 M0); Dukes' B, tumour extending into the subserosa or into non-peritonealised, pericolic, or perirectal tissue (T3 NO M0) or directly infiltrating other organs or structures and/or perforating the visceral peritoneum (T4 N0 M0); Dukes' C, metastasis in regional lymph nodes $(\mathrm{N}+)$; and Dukes' $\mathrm{D}$, distant metastasis $(\mathrm{M}+)$. Information on familial history of CRC, type of surgery, and adjuvant treatments was also obtained. Possibility of resection of the tumour for potential cure was defined as macrosopic resection of all tumoral tissue. Follow up data (vital status and, when relevant, date of death) were obtained regularly from the Registry of Digestive Tumours of the Côte d'Or through medical and administrative sources.

Abbreviations: CRC, colorectal cancer; BMI, body mass index; RR, relative risk. 


\begin{tabular}{|c|c|c|c|c|c|c|}
\hline \multirow{5}{*}{$\begin{array}{l}\text { Age at diagnosis (y)) } \\
\text { Familial history of CRC (\%) } \\
\text { BMI }\left(\mathrm{kg} / \mathrm{m}^{2}\right) \\
\text { Physical activity (\%) }\end{array}$} & \multicolumn{2}{|c|}{ Men $(n=97)$} & \multicolumn{2}{|c|}{ Women $(n=51)$} & \multicolumn{2}{|c|}{ Total $(n=148)$} \\
\hline & 65.8 & (9.3) & 62. & $(11.3)$ & 64. & 4 (10.2) \\
\hline & 17 & $(15.5 \%)$ & 10 & $(19.6 \%)$ & 25 & (16.9\%) \\
\hline & 25.8 & $(3.8)$ & 23. & (3.3) & 25 . & (3.7) \\
\hline & & & & & & \\
\hline Low & 59 & $(60.8 \%)$ & 36 & $(70.6 \%)$ & 95 & $(64.2 \%)$ \\
\hline Moderate & 23 & $(23.7 \%)$ & 13 & $(25.5 \%)$ & 36 & $(24.3 \%)$ \\
\hline High & 15 & $(15.5 \%)$ & 2 & $(3.9 \%)$ & 17 & (11.5\%) \\
\hline Alcohol intake (g/day) & 44.8 & $(39.3)$ & \multicolumn{2}{|c|}{$8.9(16.1)$} & \multicolumn{2}{|c|}{$32.4(37.3)$} \\
\hline 1 st tertile & \multicolumn{2}{|c|}{22.83} & \multirow{2}{*}{\multicolumn{2}{|c|}{$\begin{array}{l}0.70 \\
5.42\end{array}$}} & \multicolumn{2}{|c|}{-} \\
\hline 2nd tertile & \multicolumn{2}{|c|}{53.94} & & & - & \\
\hline \multicolumn{7}{|l|}{ Tobacco consumption } \\
\hline Non-smoker & 18 & $(18.6 \%)$ & 49 & $(96.0 \%)$ & 67 & $(45.3 \%)$ \\
\hline$<20$ pack-years & 36 & (37.1\%) & 1 & $(2.0 \%)$ & 37 & $(25.0 \%)$ \\
\hline$\geqslant 20$ pack-years & 43 & $(44.3 \%)$ & 1 & $(2.0 \%)$ & 44 & $(29.7 \%)$ \\
\hline Alcohol free energy intake (kcal/day) & 2440 & 16850 & 2115 & $(803)$ & 2328 & (742) \\
\hline 1 st tertile & 2107 & & 1754 & & - & \\
\hline 2nd tertile & 2684 & & 2234 & & - & \\
\hline Total energy intake (kcal/day) & 2754 & (829) & 2177 & (782) & 2555 & $(856)$ \\
\hline 1 st tertile & 2373 & & 1843 & & - & \\
\hline 2nd tertile & 2985 & & 2287 & & - & \\
\hline \multicolumn{7}{|l|}{ Tumour location (\%) } \\
\hline Colon & 49 & $(50.5 \%)$ & 39 & $(76.5 \%)$ & 88 & (49.4\%) \\
\hline Rectum & 48 & $(49.5 \%)$ & 12 & $(23.5 \%)$ & 60 & (40.6\%) \\
\hline \multicolumn{7}{|l|}{ Tumour stage (\%) } \\
\hline Dukes' A & 34 & $(35.1 \%)$ & 14 & $(27.5 \%)$ & 48 & (32.4\%) \\
\hline Dukes' B & 39 & $(40.2 \%)$ & 25 & $(49.0 \%)$ & 64 & $(43.3 \%)$ \\
\hline Dukes' C & 22 & $(22.7 \%)$ & 10 & (19.6\%) & 32 & (21.6\%) \\
\hline Dukes' D & 2 & $(2.0 \%)$ & 2 & $(3.9 \%)$ & 4 & $(2.7 \%)$ \\
\hline Adjuvant treatment (RT-CT) (\%) & 13 & (13.4\%) & 2 & $(3.9 \%)$ & 15 & $(10.1 \%)$ \\
\hline
\end{tabular}

Dietary and lifestyle data were assessed with special care. Before the case control study was set up, a pilot study was performed to compare and validate two diet history methods (a questionnaire by meal and a questionnaire with a list of foods) for assessing current dietary intake. ${ }^{17}$ This pilot study resulted in a two hour detailed qualitative and quantitative questionnaire concerning diet in the year preceding diagnosis. The questionnaire followed the pattern of meals throughout the day. It was administered within three months of diagnosis at the subject's home by a specially trained dietician who also coded the data. Nutritional data were transformed into a mean daily intake of nutrients, using a compilation food composition table ${ }^{18}$ worked out for the needs of the study, which included 318 simple foods and 188 mixed dishes. Tertiles of foods, nutrients, total energy, and alcohol free energy intakes were computed separately by sex. Tobacco consumption (summarised in pack-years) and alcohol intake (g/day) were also assessed. Physical activity was recorded as low (totally sedentary lifestyle), high (recreational or occupational activity requiring strenuous physical activity), or moderate. Information on weight and height was obtained from subjects at the time of interview. Body mass index (BMI) was calculated as weight/(heightxheight) and tertiles of BMI were computed by sex.

\section{Statistical analysis}

All data were entered into a computer based data file. Descriptive statistics (mean, SD, tertiles) were calculated for all dietary variables. Associations $\left(\chi^{2}\right.$ test $)$ and interactions (Mantel-Haenszel $\chi^{2}$ test) were tested for all adjustment variables. Death from any cause within five and 10 years of diagnosis was the end point. A multivariate Cox proportional hazards model was applied using SAS (8th version). ${ }^{19}$ The hypothesis of proportionality of risk over time was assessed for each covariate using the graphical method ${ }^{20}$ and, when needed, by testing the statistical significance of an interaction term between the explanatory variable and time. KaplanMeier survival curves and crude log rank tests were calculated for all variables before multivariate analysis. Because patients with Dukes' A and B tumours had very similar survival curves and because patients with Dukes' D tumours resected for potential cure were rare (four patients) and had a crude five year survival $(25.0 \%)$ comparable with Dukes' C patients $(28.1 \%)$, the tumour stage variable was set as Dukes' A-B in one group and Dukes' C-D in another group. In multivariate survival analysis, the relative risk of death (RR) estimates for nutrient intake and their 95\% confidence intervals (95\% CI) were adjusted for age, sex, tumour location (rectum or colon), and stage (Dukes' A-B or C-D). Energy intake was also entered into the models as an adjustment variable, except for nutrients presenting with Pearson correlation coefficients $(\rho)$ with an energy intake over 0.80 to avoid co-adjustment.

\section{RESULTS}

Among the 171 patients included in the initial case control study, 19 had undergone palliative surgery or no surgery, one had undergone potential curative surgery but died seven days after surgery, and three had undetermined tumour stage. These 23 patients were therefore excluded from the survival study. The characteristics of the remaining 148 patients (97 men, 51 women) are presented in table 1 . None was lost to follow up.

\section{Five year survival}

Forty six patients $(31.1 \%)$ died within five years of diagnosis. In univariate analysis, tumour stage was the strongest variable related to five year survival as 20 (17.9\%) of 112 Dukes' A-B patients and $26(72.2 \%)$ of 36 Dukes' C-D patients died within five years $(p<0.0001)$. Six $(12.0 \%)$ of 50 patients with a high energy intake, $22(45.8 \%)$ of 48 patients with a moderate energy intake, and $18(36.0 \%)$ of 50 patients with a low energy intake died within five years $(\mathrm{p}=0.0007)$. Age under 65 years $(p=0.17)$, female sex $(p=0.25)$, and colonic location of the tumour $(p=0.22)$ were also associated with better five year survival, but these relationships were not statistically significant. There was a significant association between age and 
Table 2 Adjustment variables. Multivariate survival analysis (Cox model). $n=148$ patients

\begin{tabular}{|c|c|c|c|c|}
\hline Adjustment variable & Group comparison & $\begin{array}{l}5 \text { year RR of } \\
\text { death }\end{array}$ & $95 \% \mathrm{Cl}$ & $\mathrm{p}$ Value \\
\hline Sex & Women $v$ men & & & \\
\hline Colonic tumour & & 0.39 & $(0.15 ; 0.99)$ & 0.05 \\
\hline Rectal tumour & & 1.61 & $(0.48 ; 5.39)$ & 0.44 \\
\hline Age & $\geqslant 65 v<65$ year & 1.28 & $(0.67 ; 2.45)$ & 0.45 \\
\hline Tumour stage & Dukes' C-D v Dukes' A-B & & & \\
\hline Colonic tumour & & 15.21 & $(6.03 ; 38.38)$ & $<0.0001$ \\
\hline Rectal tumour & & 3.80 & $(1.50 ; 9.65)$ & 0.005 \\
\hline Energy intake & $\mathrm{H} \vee 2 \mathrm{~L}$ & 0.18 & $(0.07 ; 0.44)$ & 0.0002 \\
\hline
\end{tabular}

$\mathrm{RR}$, relative risk; $95 \% \mathrm{Cl}, 95 \%$ confidence interval; $\mathrm{CRC}$, colorectal cancer; $\mathrm{H} v 2 \mathrm{~L}$, highest tertile compared with the two lowest tertiles.

Table 3 Five year relative risk of death according to specific foods (controlled for age, sex, tumour stage, tumour location, and energy intake)

\begin{tabular}{|c|c|c|c|c|c|c|}
\hline \multirow[b]{2}{*}{ Food } & \multirow{2}{*}{$\begin{array}{l}1 \text { st tertile } \\
\text { (Ref) }\end{array}$} & \multicolumn{2}{|c|}{ 2nd tertile } & \multicolumn{2}{|c|}{ 3rd tertile } & \multirow[b]{2}{*}{ p Value* } \\
\hline & & RR & $95 \% \mathrm{Cl}$ & RR & $95 \% \mathrm{Cl}$ & \\
\hline Meat & 1.0 & 1.32 & $(0.59 ; 2.95)$ & 1.64 & $(0.75 ; 3.58)$ & 0.21 \\
\hline Delicatessen & 1.0 & 1.28 & $(0.64 ; 2.58)$ & 0.93 & $(0.40 ; 2.14)$ & 0.96 \\
\hline Fish & 1.0 & 2.07 & $(1.00 ; 4.26)$ & 1.24 & $(0.58 ; 2.65)$ & 0.49 \\
\hline Eggs & 1.0 & 0.66 & $(0.30 ; 1.45)$ & 1.10 & $(0.52 ; 2.33)$ & 0.86 \\
\hline Fats & 1.0 & 1.44 & $(0.73 ; 2.83)$ & 0.79 & $(0.31 ; 2.02)$ & 0.91 \\
\hline Vegetables & 1.0 & 1.03 & $(0.47 ; 2.29)$ & 1.09 & $(0.49 ; 2.45)$ & 0.83 \\
\hline Fruit & 1.0 & 0.81 & $(0.38 ; 1.70)$ & 0.84 & $(0.37 ; 1.88)$ & 0.67 \\
\hline Rice and pasta & 1.0 & 0.97 & $(0.44 ; 2.14)$ & 0.97 & $(0.44 ; 2.15)$ & 0.94 \\
\hline Bread & 1.0 & 1.41 & $(0.67 ; 2.97)$ & 1.01 & $(0.43 ; 2.33)$ & 0.95 \\
\hline Sweet products & 1.0 & 0.95 & $(0.45 ; 2.03)$ & 1.02 & $(0.48 ; 2.16)$ & 0.98 \\
\hline Tea and coffee & 1.0 & 1.69 & $(0.78 ; 3.64)$ & 1.46 & $(0.64 ; 3.22)$ & 0.35 \\
\hline Dairy products & 1.0 & 0.53 & $(0.24 ; 1.15)$ & 0.63 & $(0.30 ; 1.33)$ & 0.24 \\
\hline
\end{tabular}

Ref, Reference; RR, relative risk; $95 \% \mathrm{Cl}, 95 \%$ confidence interval. *Test for linear trend.

energy intake $(p=0.001)$ but no significant interaction regarding survival $(p=0.14)$. No other association was found between adjustment variables, in particular between energy intake and tumour stage $(\mathrm{p}=0.18)$ or between BMI, physical activity, and energy intake.

The adjusted RRs of death within five years of diagnosis obtained using the Cox model are presented in tables 2-4. We found significant interactions in terms of survival between sex and tumour location $(\mathrm{p}=0.05)$ and between tumour stage and tumour location $(p=0.03)$. Interaction terms were included in the multivariate model for further analyses. Tumour stage was the strongest prognostic factor, with the effect being greater in patients with colonic tumours than in those with rectal tumours. We also observed better survival in women with Dukes' A-B rectal tumours (compared with men with Dukes' A-B colonic tumours) and in patients with Dukes' C-D rectal tumours (compared with patients with Dukes' C-D colonic tumours). Energy intake was significantly associated with increased survival. Five year relative risk of death was 1.1 (95\% CI $0.07 ; 0.50)$ for patients with moderate energy intake and 0.19 (95\% CI $0.07 ; 0.50)$ for patients with high energy intake. The first two tertiles of energy intake were merged for further analyses. RR associated with high energy intake compared with low to moderate intake was 0.18 (95\% CI $0.07 ; 0.44$ ) $(p=0.002)$. Adjusted survival curves according to alcohol free energy intake are presented in fig 1. Similar results were obtained with total energy intake (RR 0.14 (95\% CI 0.05; 0.38); $\mathrm{p}<0.0001)$. Controlling for BMI did not modify the effect of energy intake on survival. Stratified analyses were performed on tumour stage. The effect of high energy intake was stronger in patients with advanced than in those with non-advanced tumours, although the interaction term was not statistically significant: five year adjusted RR for high energy intake was 0.37 (95\% CI $0.12 ; 1.12)(p=0.08)$ for Dukes' A-B patients $\left(n=112\right.$ patients, $n^{\prime}=20$ deaths $)$ and 0.06 $(95 \%$ CI $0.01 ; 0.30)(\mathrm{p}<0.001)$ for Dukes' C-D patients $(\mathrm{n}=36$ patients, $n^{\prime}=26$ deaths). The effect of energy intake on survival was similar in both sexes. The corresponding risk for male patients $\left(n=97\right.$ patients, $n^{\prime}=33$ deaths $)$ was $0.20(95 \%$ CI $0.06 ; 0.61)(p=0.005)$ and was 0.18 (95\% CI 0.03; 0.96) $(p=0.04)$ for female patients $\left(n=51\right.$ patients, $n^{\prime}=13$ deaths $)$. Tumour location did not significantly influence the impact of energy intake on survival: five year adjusted RR of death for high energy intake $0.21(95 \%$ CI $0.06 ; 0.68)(p=0.01)$ in patients with colonic tumours ( $\mathrm{n}=88$ patients, $\mathrm{n}^{\prime}=24$ deaths) and $0.15(95 \%$ CI $0.03 ; 0.69)(\mathrm{p}=0.01)$ in patients with rectal tumours ( $\mathrm{n}=60$ patients, $\mathrm{n}^{\prime}=22$ deaths $)$.

Because tobacco and alcohol consumption were rare in women, these variables were only examined in men. They had no statistically significant effect on survival. Physical activity and BMI were not statistically related to five year survival. Patients with a familial history of CRC had slightly decreased survival compared with their counterparts (RR 0.63 (95\% CI $0.22 ; 1.79) ; \mathrm{p}=0.39)$. Adjuvant treatments had no significant effect on five year prognosis (RR 0.47 (95\% CI 0.28; 1.80); $\mathrm{p}=0.71)$. Energy intake was strongly correlated with intake of carbohydrates (correlation coefficient $\rho=0.90$ ), proteins $(\rho=0.90)$, lipids $(\rho=0.88)$, and saturated and monounsaturated fatty acids $(\rho=0.85$ and $\rho=0.86$, respectively). Therefore, energy intake was not entered into the models as an adjustment variable when studying these variables. When controlling for age, sex, stage, tumour site, and interaction terms, all macronutrients (glucids, lipids, proteins) were significantly associated with survival, with the effect being 
Table 4 Five year relative risk of death according to specific nutrients (controlled for age, sex, tumour stage, tumour location, and energy intake)

\begin{tabular}{|c|c|c|c|c|c|c|}
\hline \multirow[b]{2}{*}{ Nutrient } & \multirow{2}{*}{$\begin{array}{l}\text { 1st tertile } \\
\text { (Ref) }\end{array}$} & \multicolumn{2}{|c|}{ 2nd tertile } & \multicolumn{2}{|c|}{ 3rd tertile } & \multirow[b]{2}{*}{ p Value* } \\
\hline & & RR & $95 \% \mathrm{Cl}$ & RR & $95 \% \mathrm{Cl}$ & \\
\hline Carbohydrates $\dagger$ & 1.0 & 0.51 & $(0.25 ; 1.06)$ & 0.32 & $(0.14 ; 0.76)$ & 0.007 \\
\hline Proteinst $†$ & 1.0 & 0.73 & $(0.73 ; 1.44)$ & 0.27 & $(0.12 ; 0.63)$ & 0.002 \\
\hline Lipids† & 1.0 & 1.27 & $(0.65 ; 2.47)$ & 0.24 & $(0.09 ; 0.59)$ & 0.003 \\
\hline Fibre & 1.0 & 0.80 & $(0.37 ; 1.72)$ & 1.87 & $(0.83 ; 4.22)$ & 0.15 \\
\hline Calcium & 1.0 & 0.73 & $(0.34 ; 1.57)$ & 0.69 & $(0.28 ; 1.70)$ & 0.41 \\
\hline Iron & 1.0 & 0.69 & $(0.34 ; 1.41)$ & 0.56 & $(0.21 ; 1.46)$ & 0.21 \\
\hline Copper & 1.0 & 0.78 & $(0.37 ; 1.64)$ & 0.59 & $(0.26 ; 1.34)$ & 0.20 \\
\hline Zinc & 1.0 & 1.51 & $(0.74 ; 3.08)$ & 0.92 & $(0.38 ; 2.23)$ & 0.91 \\
\hline Vitamin A & 1.0 & 1.37 & $(0.64 ; 2.93)$ & 1.43 & $(0.71 ; 2.88)$ & 0.32 \\
\hline Beta carotene & 1.0 & 1.16 & $(0.53 ; 2.55)$ & 1.59 & $(0.74 ; 3.43)$ & 0.23 \\
\hline Vitamin B1 & 1.0 & 1.34 & $(0.67 ; 2.70)$ & 0.75 & $(0.29 ; 1.95)$ & 0.73 \\
\hline Vitamin B2 & 1.0 & 0.94 & $(0.43 ; 2.04)$ & 0.70 & $(0.31 ; 1.59)$ & 0.40 \\
\hline Vitamin B6 & 1.0 & 0.71 & $(0.32 ; 1.57)$ & 1.02 & $(0.45 ; 1.17)$ & 0.96 \\
\hline Folic acid & 1.0 & 1.40 & $(0.68 ; 2.91)$ & 1.67 & $(0.74 ; 3.78)$ & 0.21 \\
\hline Vitamin B12 & 1.0 & 1.25 & $(0.57 ; 2.77)$ & 1.53 & $(0.73 ; 3.21)$ & 0.25 \\
\hline Vitamin C & 1.0 & 1.01 & $(0.47 ; 2.16)$ & 1.11 & $(0.50 ; 2.49)$ & 0.79 \\
\hline Vitamin D & 1.0 & 1.10 & $(0.49 ; 2.44)$ & 1.46 & $(0.73 ; 2.93)$ & 0.29 \\
\hline Vitamin $\mathrm{E}$ & 1.0 & 2.09 & $(0.97 ; 4.51)$ & 1.43 & $(0.62 ; 3.31)$ & 0.44 \\
\hline Vitamin PP & 1.0 & 1.16 & $(0.57 ; 2.34)$ & 1.15 & $(0.45 ; 2.91)$ & 0.73 \\
\hline Pantothenic acid & 1.0 & 0.94 & $(0.45 ; 1.95)$ & 1.04 & $(0.44 ; 2.44)$ & 0.95 \\
\hline Biotine & 1.0 & 1.29 & $(0.62 ; 2.75)$ & 1.12 & $(0.50 ; 2.50)$ & 0.76 \\
\hline Cholesterol & 1.0 & 0.80 & $(0.40 ; 1.62)$ & 1.10 & $(0.47 ; 2.61)$ & 0.97 \\
\hline Saturated fatty acids $\dagger$ & 1.0 & 1.20 & $(0.62 ; 2.33)$ & 0.20 & $(0.08 ; 0.49)$ & 0.0008 \\
\hline Monounsat. fatty acids $\dagger$ & 1.0 & 0.77 & $(0.39 ; 1.52)$ & 0.35 & $(0.15 ; 0.78)$ & 0.01 \\
\hline Polyunsat. fatty acidst & 1.0 & 0.72 & $(0.34 ; 1.53)$ & 0.52 & $(0.25 ; 1.10)$ & 0.09 \\
\hline
\end{tabular}

$\mathrm{RR}$, relative risk; $95 \% \mathrm{Cl}, 95 \%$ confidence interval

*Test for linear trend.

†Not adjusted for energy intake because of Pearson correlation coefficients with energy intake over 0.80 .

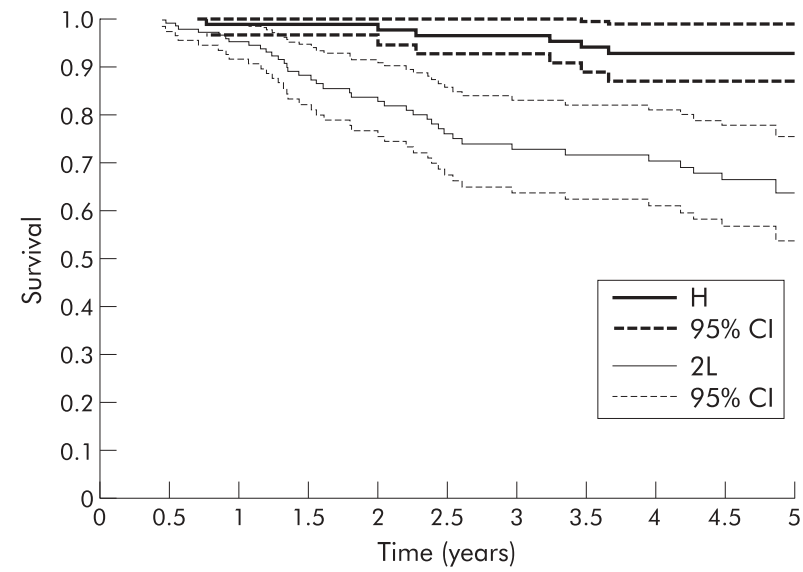

Figure 1 Five year estimated survival curves according to the energy intake groups (highest $(\mathrm{H})$ versus two lowest (2L) tertiles), after controlling for age, sex, stage, tumour location, and interaction terms (Cox model). $\mathrm{n}=148$ patients. $95 \% \mathrm{Cl}, 95 \%$ confidence intervals.

strongest for lipids, especially saturated and monounsaturated fatty acids. When controlling for energy intake, no other dietary variable was found to have any significant influence on survival.

\section{Survival between five and $\mathbf{1 0}$ years after diagnosis}

Ten years after diagnosis, 70 patients $(47.3 \%)$ were dead while none was lost to follow up. Within the 10 year period, the hypothesis of proportionality of risk was not verified for tumour stage or energy intake. A separate survival analysis was therefore performed on those who had survived the first five years. The assumption of proportionality of risk was verified for all variables in this group. During this period, only tumour location had a significant prognostic role (RR of death for rectal versus colonic location 3.12 (95\% CI 1.32;7.35), $\mathrm{p}=0.01$ ), but not tumour stage, age, or sex. None of the energy, food, or nutrient intake variables were related to survival between five and 10 years.

\section{DISCUSSION}

In our series, five year survival in patients operated on for cure of CRC was influenced by the pre-diagnosis diet. While controlling for known prognostic factors, high energy intake, as a result of high lipid, protein, and carbohydrate intake, was strongly related to increased survival.

Because our population was included in a cancer registry, we had precise data on the tumours (histopathological diagnosis, stage, location, and treatment) and exhaustive and prolonged follow up data. Dietary data were collected with the objective of limiting potential bias due to the retrospective assessment of prognostic factors: a pilot study validated a questionnaire specifically designed for CRC risk factors, and the home face to face detailed interview was performed shortly after diagnosis by trained dieticians. As adjuvant treatments were rare at the time of inclusion (1985-1987), they did not interact with our results. Such a study would be more difficult to design today as chemotherapy and radiation therapies significantly modify the course of the disease. Stage was included a priori as an adjustment variable and our results confirm the importance of tumour extension on five year survival. ${ }^{21}$ Tumour location was found to be a significant interaction factor for five year survival in our study and has been mentioned as a significant prognostic factor in previous studies. ${ }^{8}$ Moreover, rectal location was the only significant 10 year prognostic factor, making it necessary to adjust for this parameter. Sex and age were included in our multivariate models because of their prognostic roles in overall and CRC specific survival, ${ }^{78}$ and because they influence dietary intake.

As intakes of most nutrients tend to be positively associated with total energy intake, we decided to control for energy intake in our multivariate models. In addition, total energy intake had already been identified as a prognostic factor in 
CRC. ${ }^{10}$ Nevertheless, for some variables which are strongly correlated with energy intake, this method could lead to coadjustment, and we avoided it for macronutrients and some fatty acids. We computed both total and alcohol free energy intakes, but alcohol free energy intake was kept for further analysis, as alcohol has been shown to be a separate risk factor for colorectal tumours. ${ }^{14}$ In this study, alcohol by itself was not associated with survival.

Some limitations of our data set must be discussed. Our study was initially designed to assess risk factors, not prognostic factors, which led to collection of the pre-diagnosis diet. However, some authors have shown that pre- and post-diagnosis diets tended to be similar in cancer patients, ${ }^{22}$ suggesting that high energy intake may truly influence the course of the disease.

We cannot exclude recall bias as dietary intake was retrospectively assessed. This bias may be reinforced in patients presenting with a digestive cancer and interviewed for their dietary habits. In CRC, for some variables (tobacco and alcohol consumption and CRC familial history) it has been shown that disease stage could change the strength of associations with risk. These variations according to tumour stage have not been found for energy intake in studies of CRC aetiological factors. ${ }^{23}$ In our population, we did not observe any statistically significant interaction between tumour stage and energy intake.

Another limitation of our study is potential selection bias. As a common feature of retrospective assessment of risk factors of death, only surviving patients participated in the dietary interview, and among them $20.1 \%$ refused. Looking for a potential effect of diet on CRC survival, we decided not to include incurable patients. Extrapolation of our results to palliative treated patients should therefore not be attempted. However, progress in chemotherapy has led to longer survival of patients with metastatic disease, making it worthwhile to test our findings in such a population. Our study was conducted on a limited sample size population leading to restricted power. Thus we cannot exclude a specific effect of some food or nutrient on prognosis. Dietary and nutrient variables showing no significant influence on prognosis in our work should therefore be studied in larger series.

We had no data on mortality specifically related to CRC. Nevertheless, the beneficial prognostic effect of high energy intake seems to be related specifically to CRC in our study. In the Cox model, the impact of energy intake on survival was greater at advanced stages of disease (Dukes' C-D tumours for which death is likely to be strongly related to CRC) than in patients with Dukes' A-B tumours. As death specifically related to CRC mainly occurs within six years of diagnosis, ${ }^{24}$ it is not surprising that tumour stage and energy intake were identified as prognostic factors only within five years of diagnosis, but not between five and 10 years.

Dietary prognostic factors of CRC were examined in only one study in 1989 by Slattery and colleagues. ${ }^{10}$ These authors observed a beneficial impact of high energy intake on CRC, the effect being strongest within two years of diagnosis (RR 0.49). High protein and lipid intake also improved survival but these relationships did not reach statistical significance. The study had several limitations. It was conducted in Utah and most of the participants were Mormons who have specific dietary habits (prohibition of tea, coffee, alcohol, and tobacco consumption, low meat and high fibre diet). Dietary data collection was performed within six months of diagnosis leading to potential recall bias. Whether or not a curative surgical procedure could be performed was not considered as a prognostic factor.

Despite these and our own limitations, the association between increased survival and high energy intake was consistently found. In order to evaluate this relationship, it is first necessary to discuss the possibility that patients with the shortest survival had a decreased ability to eat because of ongoing underlying disease. Our inclusion criteria led us to select patients with a good health status at the time of the interview: advanced tumour stages were rare and all patients survived curative surgery. Dietary intake was considered within the year that preceded the diagnosis and patients' dietary habits were unlikely to be sharply modified within this period. ${ }^{22}$ In addition, we had shown in the initial case control study that our patients with CRC had higher energy intakes than controls, ${ }^{2}$ proving that their ability to eat was not altered. Therefore, it seems unlikely that our findings are mostly due to a decreased ability to eat at the time of diagnosis in poor survivors.

How high energy intake improves survival of CRC patients remains unclear. As high total caloric intake has been identified as a risk factor for CRC, especially in the same population, ${ }^{2}$ it may seem paradoxical that it also participates in increasing survival. However, high energy intake may result in the development of specific forms of CRC with a better prognosis. Another explanation has been suggested by Slattery and colleagues. ${ }^{10}$ Because patients with high pre- and post-diagnosis dietary intake would form greater body stores of nutrients, they may live longer than their counterparts who are able to eat less. According to this interpretation, dietary intake and body stores would reinforce immunity and could have an indirect effect on cancer recurrence or growth. However, we did not observe any association between CRC survival and BMI. Experiments tend to support an opposing phenomenon, as energy restriction increases the natural killer cell activity involved in antitumoral immunity. ${ }^{25}$ But such experiments were conducted in healthy patients. Moreover, it has been proved that natural killer cell activity is specifically linked to some polyunsaturated fatty acids and not to global energy intake. ${ }^{27}$ Longer survival because of reinforced antitumoral immunity due to greater nutrient intake and body stores should be observed with other cancers. It has been observed in prostate cancer ${ }^{12}$ but not in breast cancer where, on the contrary, high energy intake was associated with decreased survival. ${ }^{28}$ But in these cancers, fatty acid intake, which is strongly correlated with energy intake, could have a specific prognostic role because of its influence on hormonal metabolism. ${ }^{29}$

In conclusion, high energy intake was strongly associated with prolonged survival in patients who underwent potentially curative surgery for CRC. This prognostic effect was stronger in advanced than in local stage disease and may be specifically related to CRC mortality. Biological explanations for this phenomenon remain unclear. Larger series should be used to investigate dietary influence on CRC survival before intervention studies are conducted, but our results should prompt nutritional evaluation and follow up in CRC patients.

\section{ACKNOWLEDGEMENTS}

The authors wish to thank Brigitte Lieubray, Claude Grillet, and Claude Belghiti who performed the interviews, and Drs Bataillon, Bedenne, Carli, Gambert, Garaudet, Hillon, Jacquot, Klepping, Massart, Meny, Riot, Roy, and Villand for advising their patients to participate. The case control study from which this data set has been extracted was supported by the Institut National de la Santé et de la Recherche Médicale (CRE 87-8011), the Europe Against Cancer Program, and the Regional Council of Burgundy.

\section{Authors' affiliations}

X Dray, M-C Boutron-Ruault, S Bertrais, D Sapinho, Institut Scientifique et Technique de l'Álimentation et de la Nutrition, INSERM U557, CNAM, 5 rue Vertbois, 75003 Paris, France

A-M Benhamiche-Bouvier, J Faivre, Registre des Cancers Digestifs, Faculté de Médecine, 7 Bd Jeanne d'Arc, 21709 Dijon cedex, France

\section{REFERENCES}

1 Howe GR, Aronson KJ, Benito E, et al. The relationship between dietary fat intake and risk of colorectal cancer: evidence from the combined analysis of 13 case-control studies. Cancer Causes Control 1997;8:215-28. 
2 Boutron-Ruault MC, Senesse P, Meance S, et al. Energy intake, body mass index, physical activity, and the colorectal adenoma-carcinoma sequence. Nutr Cancer 2001:39:50-7.

3 Bostick RM Nutrition and colon cancer prevention. Nestle Nutr Workshop Ser Clin Perform Programme 2000;4:67-85.

4 Norat T, Riboli E. Meat consumption and colorectal cancer: a review of epidemiologic evidence. Nutr Rev 2001;59:37-47.

5 Trock B, Lanza E, Greenwald P. Dietary fiber, vegetables, and colon cancer: critical review and meta-analyses of the epidemiologic evidence. J Natl Cancer Inst 1990;82:650-61.

6 Terry $\mathbf{P}, \mathrm{Hu} F B$, Hansen $\mathrm{H}$, et al. Prospective study of major dietary patterns and colorectal cancer risk in women. Am J Epidemiol 2001;154:1143-9

7 Gatta G, Faivre J, Capocaccia R, et al. Survival of colorectal cancer patients in Europe during the period 1978-1989. Eur J Cancer 1998;34:2176-83.

8 Cyvoct C, Quantin C, Broet P, et al. Prognostic factors of recurrence and/or death in colorectal cancer: multistate modeling. Rev Epidemiol Sante Publique 1999;47:619-25.

9 Monnet E, Boutron MC, Faivre J, et al. Influence of socioeconomic status on prognosis of colorectal cancer. A population-based study in Cote D'Or, France. Cancer 1993;72:1165-70.

10 Slattery ML, French TK, Egger M, et al. Diet and survival of patients with colon cancer in Utah: is there an association? Int J Epidemiol 1989; 18:792-7

11 Goodman MT, Kolonel LN, Wilkens LR, et al. Dietary factors in lung cancer prognosis. Eur J Cancer 1992;28:495-501.

$12 \mathrm{Kim}$ DJ, Gallagher RP, Hislop TG, et al. Premorbid diet in relation to survival from prostate cancer (Canada). Cancer Causes Control 2000;11:65-77.

13 Holmes MD, Stampfer M, Colditz GA, et al. Dietary factors and the survival of women with breast carcinoma. Cancer 1999;86:826-35.

14 Boutron MC, Faivre J, Dop MC, et al. Tobacco, alcohol, and colorectal tumours: a multistep process. Am J Epidemiol 1995;141:1038-46.

15 Dukes C. The classification of the cancer of the rectum. J Pathol Bacteriol 1932; 35:323-32

16 Sobin LH, Wittekind C. TNM Classification of Malignant Tumours, 5th Edn. New York: John Wiley and Sons, Inc, 1997.
17 Boutron MC, Faivre J, Milan C, et al. A comparison of two diet history questionnaires that measure usual food intake. Nutr Cancer 1989; 12:83-91.

18 Lieubray-Bornet B, Grillet-Cousin N, Belghiti-Desprat C, et al. Food Composition Table for the Analysis of European Multicentric Studies. Lyon, France: Oza reproduction, 1993.

19 The PHREG Procedure. Preliminary Documentation. Cary, NC: SAS institute Inc., 1991.

20 Kay R. Goodness of fit methods for the proportional hazards regression model: a review. Rev Epidemiol Sante Publique 1984;32:185-98.

21 Conroy T, Adenis A. Standards, Options, and Recommendations for the surveillance after treatment in cancer of the colon. The SOR Working Group "Cancer du Colon de la Federation Nationale des Centres de Lutte Contre le Cancer". Bull Cancer 1998;85:152-9.

22 Bruning PF, Egger RJ, Gooskens AC, et al. Dietary intake, nutritional status and well- being of cancer patients: a prospective study. Eur J Cancer Clin Oncol 1985;21:1449-59.

23 Slattery ML, Edwards SL, Samowitz W. Stage of colon cancer at diagnosis: implications for risk factor associations? Int J Epidemiol 1998;27:382-7.

24 Verdecchia A, De Angelis R, Capocaccia R, et al. The cure for colon cancer: results from the EUROCARE study. Int J Cancer 1998;77:322-9.

25 Barone J, Hebert JR, Reddy MM. Dietary fat and natural-killer-cell activity. Am J Clin Nutr 1989;50:861-7.

26 Kelley DS, Daudu PA, Branch LB, et al. Energy restriction decreases number of circulating natural killer cells and serum levels of

immunoglobulins in overweight women. Eur J Clin Nutr 1994;48:9-18.

27 Thies F, Nebe-von-Caron G, Powell JR, et al. Dietary supplementation with eicosapentaenoic acid, but not with other long-chain n-3 or n-6 polyunsaturated fatty acids, decreases natural killer cell activity in healthy subjects aged $>55$ y. Am J Clin Nutr 2001;73:539-48.

28 Saxe GA, Rock CL, Wicha MS, et al. Diet and risk for breast cancer recurrence and survival. Breast Cancer Res Treat 1999;53:241-53.

29 Rao GN. Influence of diet on tumours of hormonal tissues. Prog Clin Biol Res 1996;394:41-56. 